\title{
ARBORIZAÇÃO URBANA NA PERCEPÇÃO DA POPULAÇÃO DO DISTRITO DE IARA NO CEARÁ
}

\author{
URBAN AFFORESTATION IN THE DISTRICT OF IARA POPULATION'S \\ PERCEPTION IN CEARÁ
}

\author{
Ediglécia Pereira de Almeida ${ }^{1}$, Samara Paulo dos Santos Fernandes², Patrícia Carneiro Souto ${ }^{3}$
}

\begin{abstract}
RESUMO
Uma forma de minimizar os problemas ambientais ocasionados pelo crescimento desordenados das cidades é a arborização urbana que pode proporcionar benefícios como, por exemplo, conforto térmico e redução da poluição sonora. Foram aplicados 150 formulários semiestruturados. A aplicação dos formulários se deu de forma sistemática, onde os mesmos foram divididos entre seis ruas do Distrito de lara-CE. Os dados obtidos indicaram que $24,0 \%$ dos entrevistados consideram a localidade pouco arborizada, $64 \%$ acham que a arborização existente nesta localidade é razoável e 12,0\% consideram muito arborizada. Quanto ao manejo da arborização, $85,0 \%$ dos entrevistados opinaram que a responsabilidade é da prefeitura, $33 \%$ opinaram que a responsabilidade é da própria população e $7 \%$ opinaram que o manejo da arborização urbana é de responsabilidade das companhias elétricas. As principais vantagens da arborização urbana indicadas foram: sombra $96,7 \%$, redução na temperatura $61,3 \%$ e beleza estética $52 \%$ e as principais desvantagens foram redução na iluminação pública $56 \%$, sujeira de ruas e calçadas $48,7 \%$ e problemas com redes elétrica e telefônica $42,0 \%$. A análise da percepção ambiental dos moradores do Distrito de lara mostrou que mais da metade dos entrevistados desconheciam o significado do termo arborização urbana, no entanto compreendem os benefícios proporcionado pelas árvores na localidade.
\end{abstract}

Palavras-chave: Planejamento urbano; Conforto térmico; Benefícios ambientais; Espécies nativas; Nim indiano.

\begin{abstract}
One way of minimizing the environmental problems caused by the disorderly growth of cities is the urban afforestation which can provides benefits such as thermal comfort and reduction of noise pollution. A total of 150 semi-structured forms were applied. The forms application took place in a systematic way, being divided among six streets of the District of lara-CE. The data obtained indicate that $24.0 \%$ of the interviewees consider the locality to be poorly forested, $64 \%$ believe that there is reasonable afforestation in this locality, and $12.0 \%$ consider it too woody. Regarding the management of the afforestation, $85.0 \%$ of the respondents said that it is the city's responsibility, $33 \%$ said that the responsibility belongs to the population and $7 \%$ said that the management of urban trees is the responsibility of the electric companies. The main advantages of urban afforestation indicated were: shade $96.7 \%$, reduction in temperature $61.3 \%$ and beauty $52 \%$ and the main disadvantages were reduction in public lighting $56 \%$, street and pavement dirt $48.7 \%$ and problems with electric and telephone networks $42.0 \%$. The analysis of the environmental perception of the inhabitants of the District of lara showed that more than half of the interviewees did not know the meaning of the term urban afforestation, but understood the benefits provided by the trees in the locality.
\end{abstract}

Keywords: Urban planning; Thermal comfort; Environmental benefits; Native species; Indian Nim.

Recebido em 28.03.2019 e aceito em 25.06.2019

1 Engenheira Florestal. Mestranda do Programa de Pós-Graduação em Ciências Florestais da Universidade Federal de Campina Grande. Patos/PB. Email: ediglecia.almeida@hotmail.com

2 Engenheira Florestal. Mestranda do Programa de Pós-Graduação em Ciências Florestais da Universidade Federal de Campina Grande. Patos/PB. Email: samara.paulo@hotmail.com

3 Engenheira Florestal. Professora da Unidade Acadêmica de Engenharia Florestal, Universidade Federal de Campina Grande, Campus de Patos. Patos/PB. Email: pcarneirosouto@yahoo.com.br 


\section{INTRODUÇÃO}

A expansão demográfica descontrolada que vem ocorrendo na sociedade urbana, no decorrer das últimas décadas, tem causado alterações sociais e também estruturais no espaço urbano como por exemplo, acentuação das desigualdades sociais no meio urbano, remoção da cobertura vegetal em detrimento de construções, que por consequência alteram o microclima, elevam a poluição do ar, aumentam o número de ruídos nos centros urbanos, entre outros problemas. Esse processo desenfreado de expansão dos centros urbanos tem provocado degradação ambiental pela remoção da cobertura vegetal o que compromete diretamente a qualidade de vida das pessoas que habitam estas cidades (ZEM; BIONDI, 2014).

A arborização urbana pode ser definida como toda cobertura vegetal de porte arbóreo que estejam presentes na zona urbana, e que ocupam locais como: áreas livres de uso público e potencialmente coletivas, estão presentes ainda em áreas livres particulares e podem ser encontradas acompanhando o sistema viário (CEMIG, 2011).

Uma forma de minimizar os problemas ambientais ocasionados pelo crescimento desordenados das cidades, é arborização urbana que pode proporcionar inúmeros benefícios ambientais como melhoria no microclima, redução da poluição sonora, benefícios psicoambientais como melhora do humor, redução de estresses, sensação de bem-estar, além de aumentar a valorização de imóveis em algumas ruas, uma vez que os benefícios fornecidos pela arborização urbana afeta a probabilidade da escolha do imóvel e consequentemente o aumento no valor do bem como ratificado na pesquisa de (HERMANN; HADDAD, 2005).

Inúmeros fatores positivos podem estar atrelado a arborização das cidades como por exemplo contribui para melhorar a qualidade do ar, reduzir a poluição, facilitar a infiltração da água no solo e assim evitar erosões provenientes do escoamento superficial das águas da chuva, proteger os corpos de d'água e também o solo, minimizar o efeito do vento, estabilizar o microclima, proporcionar conforto térmico e sombra, conservar as matrizes genéticas da flora nativa, atuar como abrigo natural da fauna silvestre, formação de barreiras visuais e/ou sonoras, embelezamento estéticos e melhoria da saúde mental e física da população (CEMIG, 2011).

Apesar da arborização urbana estar associada a inúmeros benefícios para as cidades, é preciso realizar um planejamento prévio para se evitar problemas futuros. A princípio é necessário escolher corretamente as espécies a serem plantadas, avaliar o mobiliário urbano aéreos e subterrâneos existente no local, observar se irá interferir o tráfego de pedestres e/ou veículos. Além disso, a população deve está integrada ao processo de arborização, desde a fase inicial de execução, quanto no manejo e manutenção dos indivíduos arbóreos (ZEM; BIONDI, 2014). Segundo Rodrigues et al. (2010), é comum se observar projetos de arborização 
fracassados, devido à falta de participação comunitária e principalmente pelo fato da população não possuir sensibilidade ambiental acerca da importância da arborização.

Outro fator a ser considerado é que a falta de planejamento na arborização urbana deixa a população vulnerável a seguir os modismos de uma determinada época na arborização de ruas e praças (NEVES; CARPANEZZI, 2009). Possivelmente esse fato acaba contribuindo para que um elevado número de árvores de uma única espécie seja introduzido na arborização urbana, essas muitas vezes exóticas, elevando assim o número dessas na arborização e consequentemente diminuindo o número de exemplares de espécies nativas nas ruas e praças.

A realização de análises sobre a percepção popular sobre a arborização urbana, realizadas através de enquetes, tem como objetivo buscar informações e expectativas da população no que diz respeito a impressão que o lugar apresenta tanto esteticamente quanto ambiental (BOBROWSKI; BIONDI, 2016).

Os estudos que tem como base essa linha de pesquisa, (RIBEIRO, 2018; LOURENÇO, 2017; SOUZA et al., 2017) podem servir como suporte para que prefeituras e gestores possam gerir tomadas de decisões ligadas às temáticas ambientais, promovem a interação homemárvore e aguçam a sua percepção em relação ao meio o qual estão inseridos, instigando o cidadão que é o usuário final da arborização urbana, a ser mais atuante em questões que merecem a sua participação.

Diante disto, o objetivo dessa pesquisa é conhecer a percepção dos moradores do Distrito de lara-CE em relação a arborização urbana desta localidade com base nas suas visões e respostas.

\section{MATERIAL E MÉTODOS}

O trabalho foi realizado no Distrito de lara que se situa no Sul Cearense localizado as margens da BR 116, nas coordenadas 702'47.4"S 3846'52.9"W e abriga uma população de 2.541 habitantes (IBGE, 2010). A coleta de dados foi realizada em abril de 2017 e na ocasião foram aplicados formulários com 13 questões fechadas (Figura1), onde os pesquisadores estabeleciam um diálogo com os entrevistados de acordo com a sua disponibilidade em responder as perguntas, podendo de acrescentar sugestões, reclamações e observações relacionadas à arborização da localidade. 


\section{I- Perfil do entrevistado}

1. Sexo:
( ) Masculino
( ) Feminino
2. Faixa etária:

( ) 18 a 20 anos

( ) Entre 21 a 40 anos

( ) Entre 41 a 60 anos

( )Mais de 60 anos

3. Escolaridade:
( ) Fundamental completo
( ) Médio completo
( ) Superior completo
( ) Sem Formação

\section{Atividade} ( ) Sem ocupação / aposentado
( ) Profissional liberal
( ) Funcionário público
( ) Contratado
II - Opinião do entrevistado

1. Sabe o que significa arborização urbana?

( ) Sim ( ) Não

2. Como classificaria o manejo da arborização na cidade?
( ) Pouco arborizada
( ) Razoavelmente arborizada
( ) Muito arborizada

3. Quais as vantagens que observa na arborização de sua cidade?
( ) Sombra
( ) Redução do impacto da chuva
( ) Preservação da biodiversidade
( ) Redução da temperatura
( ) Redução da poluição
( ) Beleza estética
( ) Não vejo vantagens

4. Quais as desvantagens você observa na arborização urbana?
( ) Sujeira de ruas e calçadas
( ) Problema com as redes elétricas ou telefônica iluminação pública
( ) Problemas nas calçadas
( ) Não vejo desvantagens
( ) Redução da

5. Na sua opinião quem é responsável pela arborização urbana?
( ) População
( ) Prefeitura
( ) Companhia elétrica

6. Se você perceber que alguém está depredando uma árvore na sua rua, o que faria?
( ) Chamaria a atenção
( ) Conversaria
( ) Denunciaria
( ) Nada
( ) Não sabe

7. A quem encaminhar reclamações relacionadas à arborização urbana?
( ) Prefeitura
( ) Não sabe
( ) Companhia elétrica
8. Como você colabora com a arborização em sua cidade?
( ) Não danificando as árvores
( ) Plantando árvores
( ) Cuidando das árvores próximas de sua residência ( ) Não fazendo nada

9. Que tipo de vegetação você escolheria na arborização urbana?
( ) Qualquer espécie
( ) Arbustos
( ) Árvores (indica alguma?)
( ) Não sabe

Figura 1. Formulário de avaliação da percepção ambiental dos moradores de lara-(CE)

Figure 1. Evaluation form of the environmental perception of the residents of lara-(CE)

Para a definição das amostras considerou-se o total da população da localidade, calculado através da metodologia (equação 1) de Triola (1999), ao nível de 95\% de significância e com margem de erro amostral de $8 \%$, considerando uma heterogeneidade da população de $50 \%$, obteve-se o total de 142 formulários, porém foram aplicados o quantitativo de 150 formulários semiestruturados de acordo com as contribuições de Novais (2017), com algumas adaptações estruturais referente a redução no número de questões aplicadas. O critério de seleção para a aplicação dos formulários foi o entrevistado ter idade mínima de 18 anos. A aplicação dos formulários se deu de forma sistemática, onde os 150 formulários foram divididos entre as seis principais ruas tentando abranger a maior parte do local. Uma vez que é um local pequeno, os formulários foram aplicados em seis setores da comunidade em uma casa sim e em 
outra não de forma alternada para garantir a representatividade local. Os dados obtidos nas entrevistas foram submetidos a análises com Software Microsoft Excel 2010 para cálculo de frequência absoluta e relativa.

onde:

$$
\text { Sample }=\frac{\frac{z^{2} P(1-P)}{e^{2}}}{1+\left(\frac{z^{2} P(1-P)}{e^{2} N}\right)}
$$

$\mathrm{N}=$ tamanho da população

$\mathrm{e}=$ margem de erro (porcentagem no formato decimal)

$z=$ escore $z$ (grau de confiança)

$\mathrm{P}=$ desvio padrão

\section{RESULTADOS E DISCUSSÃO}

Foram entrevistadas 150 pessoas sendo $66,7 \%$ do sexo feminino e $33,3 \%$ do sexo masculino. Houve uma divisão por faixa etária, sendo que $62 \%$ dos entrevistados tinham entre 18 e 40 anos (Tabela1).

Tabela 1. Perfil socioeconômico dos entrevistados de lara-Ceará Table 1. Socioeconomic profile of lara's -Ceará interviewees

\begin{tabular}{lcc}
\hline Sexo & Frequência Absoluta & Frequência Relativa (\%) \\
\hline Masculino & 51 & $33,3 \%$ \\
Feminino & 99 & $66,7 \%$ \\
\hline Faixa etária & & \\
\hline $16-20$ anos & 27 & $18 \%$ \\
$21-40$ anos & 66 & $44 \%$ \\
$41-60$ anos & 34 & $22,7 \%$ \\
Mais de 60 anos & 23 & $15,3 \%$ \\
\hline Escolaridade & & \\
\hline Fundamental completo & 68 & $45,3 \%$ \\
Médio completo & 77 & $51,3 \%$ \\
Superior completo & 1 & $0,7 \%$ \\
Sem formação & 4 & $2,7 \%$ \\
\hline Atividade desempenhada & & $32,7 \%$ \\
\hline Doméstica/Agricultor & 49 & $18,6 \%$ \\
Profissional liberal & 28 & $4,7 \%$ \\
Funcionário público & 7 & $0,7 \%$ \\
Contratado & 1 & $2,7 \%$ \\
Sem ocupação/aposentado & 65 & \\
\hline
\end{tabular}

Ao serem questionados sobre o significado do termo "arborização urbana", $37,3 \%$ dos entrevistados conheciam o significado e $62,7 \%$ revelaram que desconheciam totalmente. Sendo assim, se fez necessário uma breve explicação, para torná-los aptos a opinarem sobre o tema e 
classificarem a arborização da localidade em estudo. Diante destes dados negativos nota-se a importância de ações educativas relacionadas ao meio ambiente como por exemplo, a promoção da educação ambiental nas escolas, a nível de ensino fundamental e a nível médio, além da necessidade de ações governamentais que promovam mais ações voltadas para temáticas ambientais, pois essas seriam fundamentais para a formação de uma comunidade ou população mais consciente dos benefícios provenientes da arborização urbana.

A percepção dos entrevistados em relação à arborização do Distrito de lara-CE, mostra que $24 \%$ dos entrevistados consideram pouco arborizado, $64 \%$ acham que a arborização existente nesta localidade é razoável e apenas $12 \%$ consideram muito arborizado. Vale salientar que esta interpretação da arborização urbana é realizada de forma subjetiva, onde cada entrevistado classifica de acordo com seus próprios critérios e através de comparações com outras localidades que os mesmos conhecem (Figura 2).

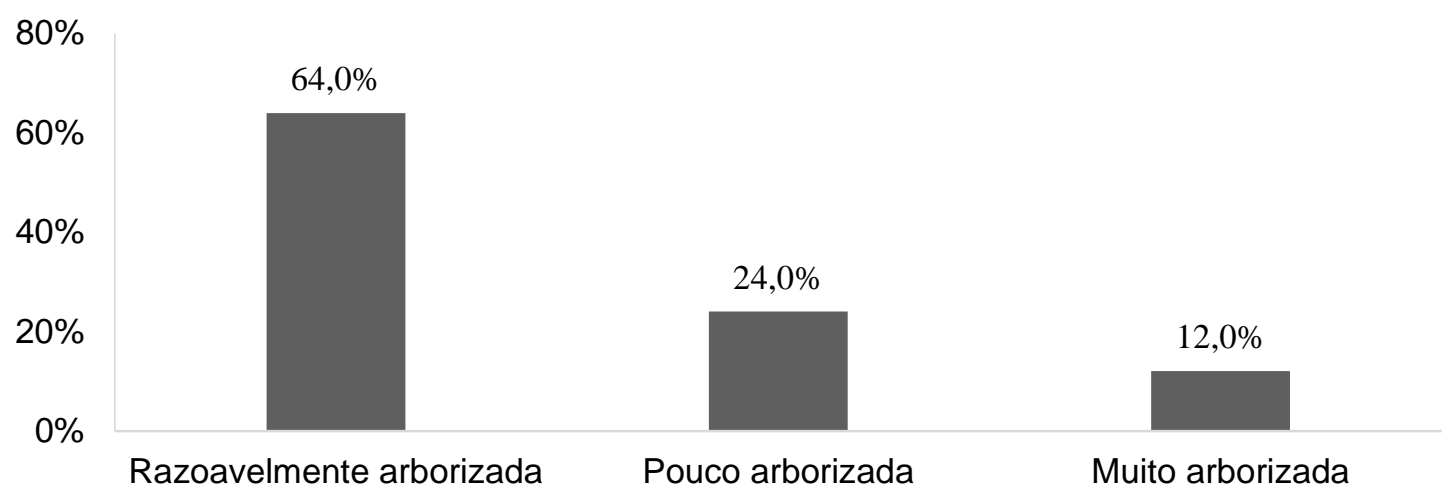

Figura 2. Percepção dos moradores de lara-Ceará em relação a arborização urbana Figure 2 Perception of lara's (CE) residents in relation to urban afforestation

De acordo com a figura acima verifica-se que a população não é insatisfeita quanto ao nível da arborização do Distrito de lara. Porém, alguns dos entrevistados ressaltaram a necessidade de aumentar o número de indivíduos arbóreos na localidade. Resultados semelhantes foram encontrados por Novais et al. (2017) e Araujo et al. (2010), em trabalhos desenvolvidos nos municípios de Santa Helena- PB e em Campina Grande-PB, onde a população revelou a necessidade de aumentar o número de indivíduos, de modo a enriquecer a arborização nessas cidades.

Quando questionados sobre as vantagens da arborização urbana, os moradores em sua maioria apontaram mais de uma opção, sendo que $96,7 \%$ deles indicaram a sombra com uma das principais vantagens, $61,3 \%$ ressaltam como vantagem a beleza estética proporcionada pela presença dos indivíduos arbóreos e 52,0\% a redução da temperatura. A sombra proveniente das copas das árvores segundo Almeida e Rondon Neto (2010), proporciona a população maior 
conforto térmico, permitindo aos pedestres transitar pelas ruas e os motoristas estacionarem seus veículos, evitando deixá-los expostos a radiação solar direta (Figura 3).

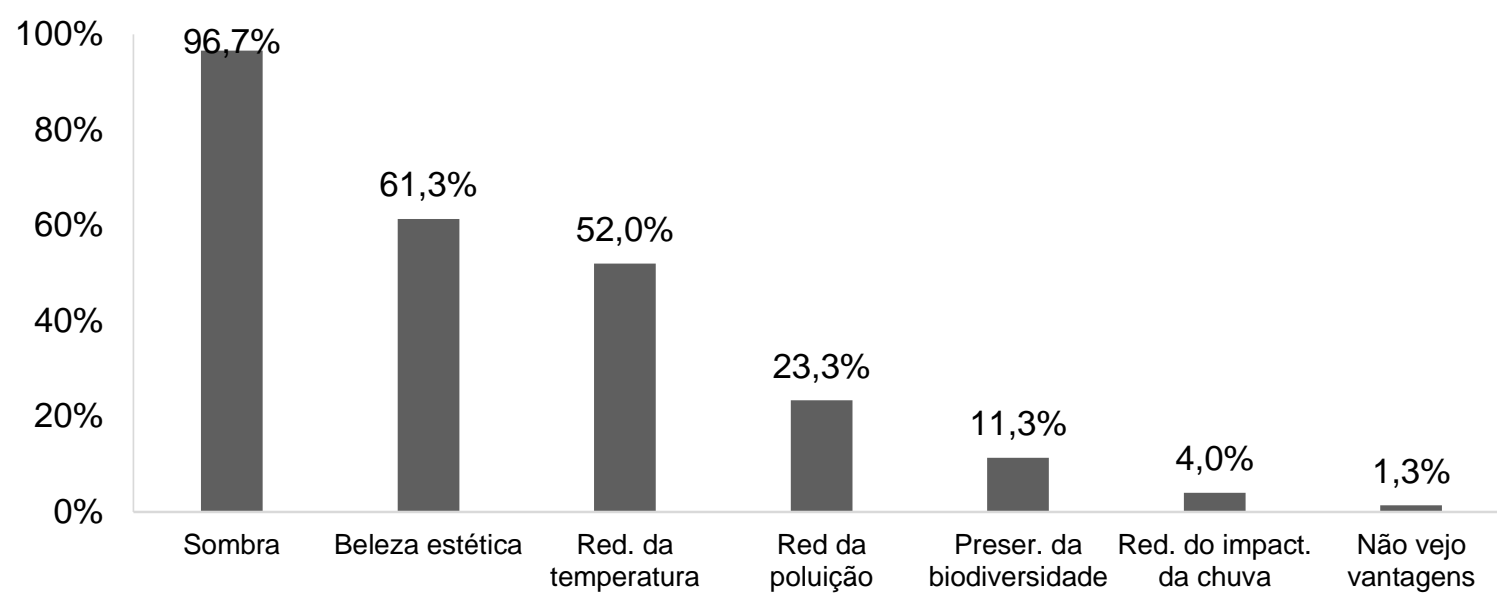

Figura 3. Opinião dos moradores de lara-Ceará em relação às vantagens da arborização urbana Figure 3. Opinion of lara's (CE) residents on the advantages of urban afforestation

Dentre as vantagens da arborização urbana citadas fica evidente a percepção dos entrevistados sobre a importância da presença de indivíduos arbóreos na zona urbana para proporcionar maior conforto térmico à população. Sombra e redução na temperatura também foram as principais vantagens encontradas em pesquisas de percepção ambiental realizadas em: Uberlândia-MG (RIBEIRO, 2009); Pires do Rio-GO (RODRIGUES et al., 2010) Três Rios-RJ (FARIA et al., 2013); e Ubá-MG (PIZZIOLO et al., 2014).

A beleza cênica que é proporcionada pela presença de flores, frutos, folhas e até mesmo pelo porte das árvores é indicada na pesquisa de Roppa et al. (2007) como atributos que podem resultar em valorização imobiliária, diante do bem-estar provocado pela arborização urbana.

Outro fator importante que vale ser ressaltado é que apenas $1,3 \%$ dos entrevistados não encontram vantagens na arborização urbana. Sendo assim, pode se notar que a maioria da população possui sensibilidade ambiental sobre os inúmeros benefícios que uma cidade arborizada pode proporcionar.

Entre as desvantagens da arborização urbana os entrevistados citaram a redução da iluminação pública 56,0\% como principal desvantagem da arborização urbana, seguido da sujeira de ruas e calçadas $48,7 \%$, dos problemas relacionados às redes elétricas ou telefônicas $42,0 \%$, problemas relacionados as calçadas $18,7 \%$ e os que não observam desvantagens na arborização 16\%, (Figura 4). 


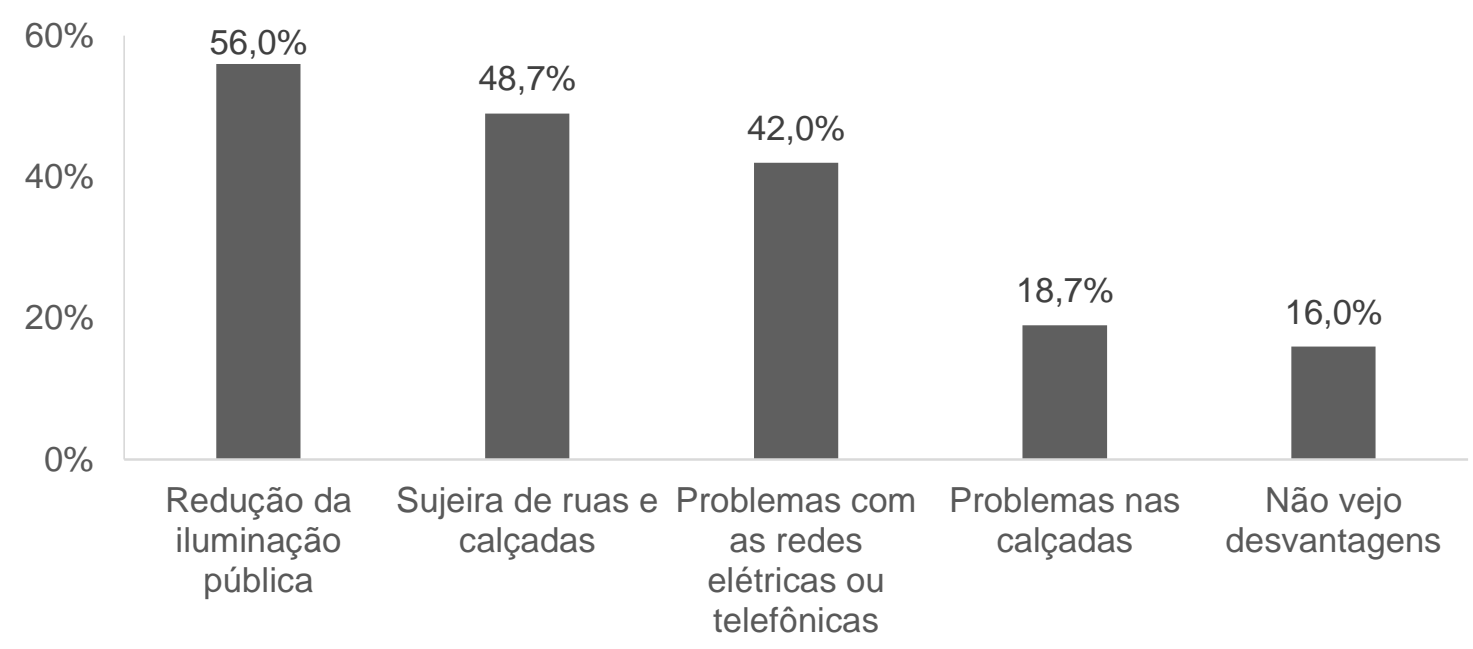

Figura 4. Opinião dos moradores de lara-Ceará em relação às desvantagens da arborização urbana Figure 4. Opinion of lara's (CE) residents on the disadvantages of urban afforestation

As principais desvantagens indicadas pela população dizem respeito a falta de planejamento como é o caso da redução na iluminação pública e os problemas com rede elétricas ou telefônicas, esses problemas poderiam ser minimizados se os gestores municipais tivessem a disposição dos moradores profissionais da área para a tomada de ações essenciais em relação à arborização urbana como por exemplo, a implantação correta da árvore a ser implantada, distância mínima entre calçadas entre outras questões. Segundo Ribeiro (2009), arborização urbana deve ser realizada baseada em espécies adaptadas as condições locais e que seu desenvolvimento não prejudique a população, a autora salienta ainda a necessidade de atividades manejo adequado e execuções de podas, realizadas da maneira correta, visando o bem-estar da população diante uma arborização adequada e bem planejada.

Em um estudo desta mesma natureza realizado por Silva et al. (2016) no município de Iporá-GO a população indicou como principais desvantagens: a redução da iluminação 36,36\%, a sujeira provocada pelas folhas $33,33 \%$ e os problemas na rede elétrica $31,82 \%$. Resultados diferentes foram encontrados por Gross et al. (2012), que ao avaliarem a percepção da arborização urbana de três bairros periféricos na cidade de Lages-SC, constataram que em nenhum dos entrevistados indicaram a redução na iluminação pública como desvantagem. Nesse estudo as principais desvantagens encontradas foram problemas com redes elétricas, telefônicas, e também a sujeira na ruas e calçadas.

Quando questionados sobre a responsabilidade da arborização urbana na comunidade, os entrevistados indicaram a prefeitura $85,0 \%$ e a própria população $33,0 \%$. Esses dados evidenciam que apesar de boa parte dos entrevistados denotarem a prefeitura como principal responsável pela arborização, um percentual expressivo dos entrevistados não se excluiu das responsabilidades que os mesmos possuem como cidadãos, tendo em vista a importância da participação de todos, no entanto, a luz do Artigo 182 parágrafo 3 da Constituição Brasileira de 
1988 o manejo da arborização urbana é de responsabilidade das prefeituras, o qual deve estar presente estar contemplado no plano diretor das cidades de acordo com o Estatuto das Cidades, lei 10.257/2001 (Figura 5).

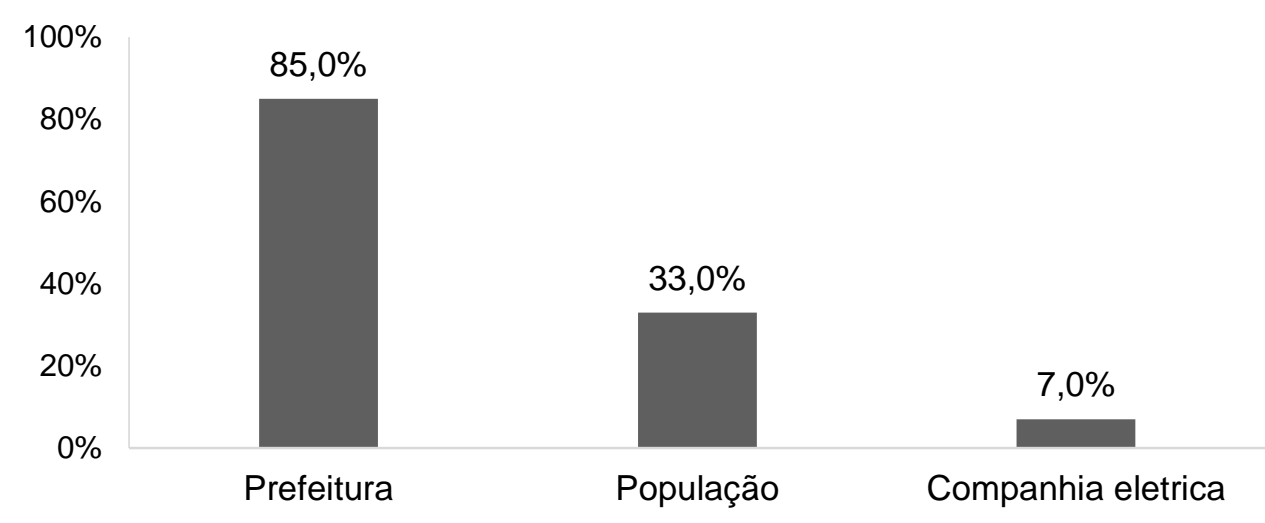

Figura 5. Opinião dos moradores de lara-Ceará em relação a responsabilidade do manejo da arborização urbana

Figure 5. Opinion of lara's (CE) residents regarding the responsibility of the urban afforestation management

O processo de urbanização das cidades se dá de forma desordenada e sem planejamento, pensar na arborização urbana é fundamental para oferecer à população uma "melhoria no microclima" e um ambiente com "beleza estética", enquanto que os efeitos negativos como os problemas com a "redução da iluminação pública", e "destruição de calçadas", citados pelos entrevistados, possam ser minimizados com a implantação de um plano diretor que contemplem as questões relacionadas à implantação e ao manejo da arborização urbana com a orientação de profissionais da área.

Em trabalhos realizados por (SOUZA et al., 2017) em Patos - PB, a prefeitura é apontada pelos entrevistados como responsável pela arborização urbana assim como nesta pesquisa. Resultados diferentes foram encontrados por (SANTOS et al., 2018) nos municípios de Tefé-AM onde a população se auto intitulou como a principal responsável pela arborização.

Os entrevistados foram questionados sobre a sua postura se observassem alguém depredando uma árvore. Do total entrevistado, 52,0\% revelaram que conversaria, 22,7\% não sabiam o que fazer, $12,7 \%$ dos entrevistados revelaram que não fariam nada, $7,3 \%$ chamariam a atenção e apenas 5,3\% opinaram que fariam uma denúncia (Figura 6). Os resultados encontrados aqui são diferentes dos de $\mathrm{Ho}$ et al. (2015), onde 40,0\% dos entrevistados revelaram que chamariam atenção e apenas $23,0 \%$ revelaram que tentariam estabelecer uma conversa. 


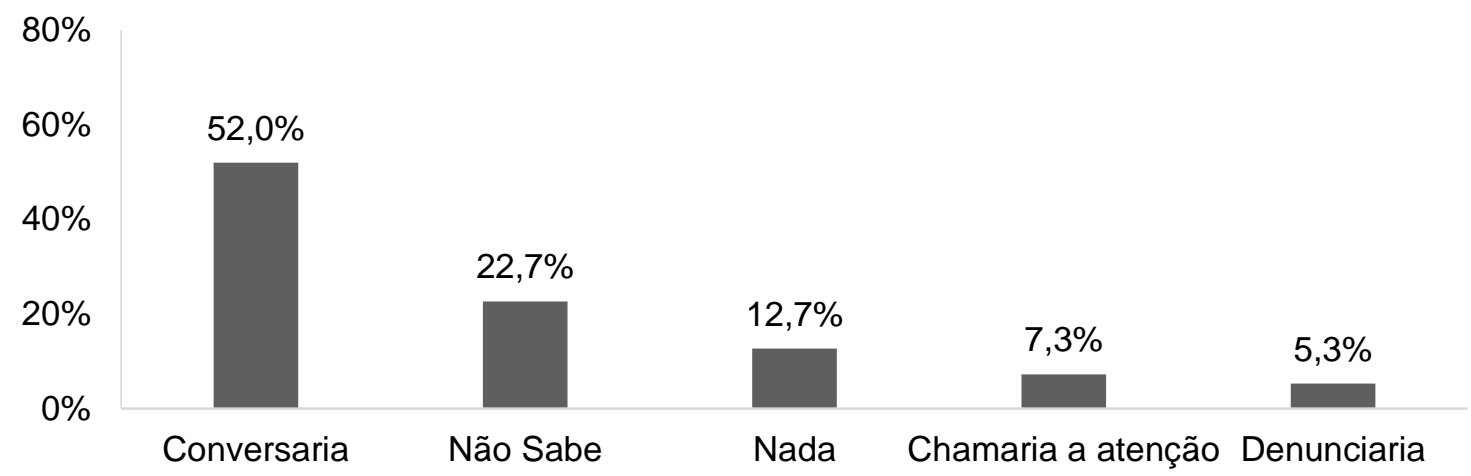

Figura 6. Atitude dos moradores de lara-Ceará em relação se observassem alguém depredando uma árvore em lara, Ceará

Figure 6. Attitude of lara's (CE) residents in case they observe someone vandalizing a tree in lara, Ceará

Observa-se pelas respostas que $52,0 \%$ do total dos entrevistados tomariam a atitude de tentar estabelecer uma conversa, no entanto, grande parte das pessoas que enfatizaram isso, relataram o receio de tomar tal ação em virtude de não saberem a quem reclamar caso essa conversa não fosse estabelecida de forma harmoniosa. Esse sentimento é reafirmado quando $22,7 \%$ do percentual dos entrevistados revelaram que se observassem alguém depredando uma árvore não saberiam o que fazer, e relataram que não sabem a quem reclamar em virtude do não haver "uma figura pública" a quem eles possam recorrer/procurar diante de tais situações. $A$ resposta dos entrevistados para essa variável revela a falta de políticas públicas atuantes e órgãos ativos que priorizem a arborização urbana como um bem comum a todos.

Os entrevistados foram questionados se diante da necessidade de recorrer a alguém, prestar queixas ou reclamações sobre vandalismos contra porte arbóreo público, a quem eles encaminhariam as possíveis reclamações relacionadas a arborização urbana (Figura 7).

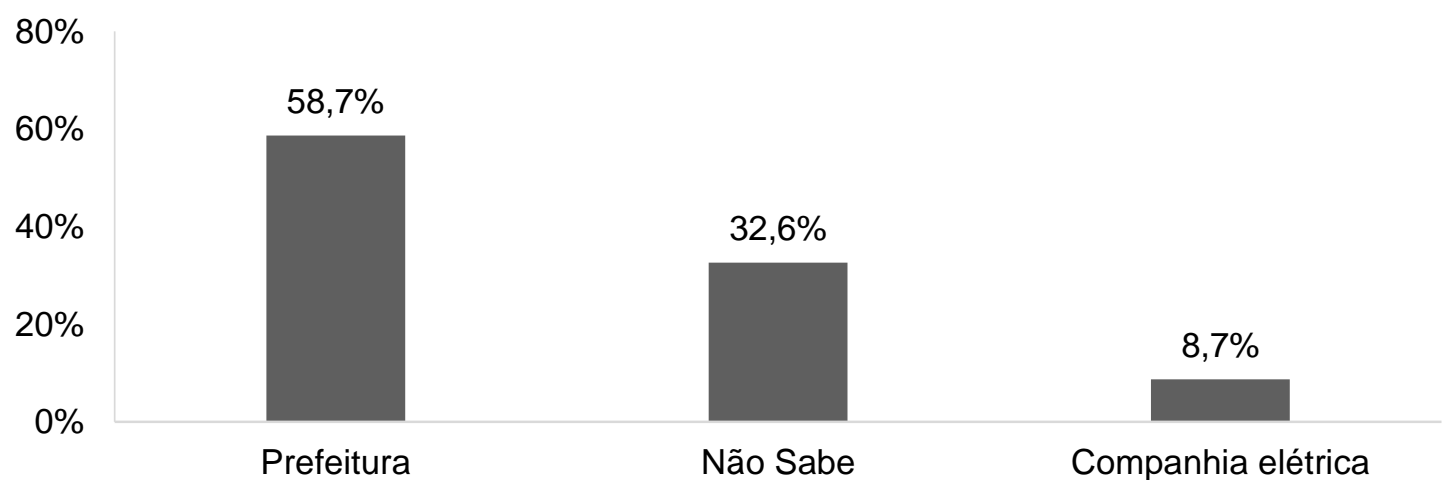

Figura 7. A quem os participantes dessa pesquisa encaminhariam possíveis reclamações diante ações de vandalismos contra a arborização de lara Ceará

Figure 7. To whom the participants of this research would send possible complaints about vandalism actions against the afforestation of lara (CE) 
Observou-se que 58,7\% dos entrevistados se direcionariam a prefeitura para efetuar possíveis reclamações ou queixas, 32,6\% não sabem a quem encaminhar suas reclamações e $8,7 \%$ responderam que procurariam a empresa responsável pela distribuição de energia elétrica na localidade.

A inexistência de gestores comprometidos com as questões ambientais, os quais as pessoas possam se dirigir para efetuar reclamações e/ou sugestões e de leis municipais rígidas acabam contribuindo para a susceptibilidade dessas áreas a ações de vândalos e, consequentemente a desvalorização dos patrimônios públicos.

Os participantes da pesquisa também foram questionados se indicariam alguma espécie vegetal para compor a arborização do Distrito. A maioria dos entrevistados $41,3 \%$ indica algum tipo de espécie arbórea, 28,0\% revelaram que indicariam qualquer espécie, desde frutíferas a espécies arbóreas e 23,4\% revelaram não saber o que sugerir ou não quiseram opinar e 7,3\% indicariam algum tipo de arbustos (Figura 8).

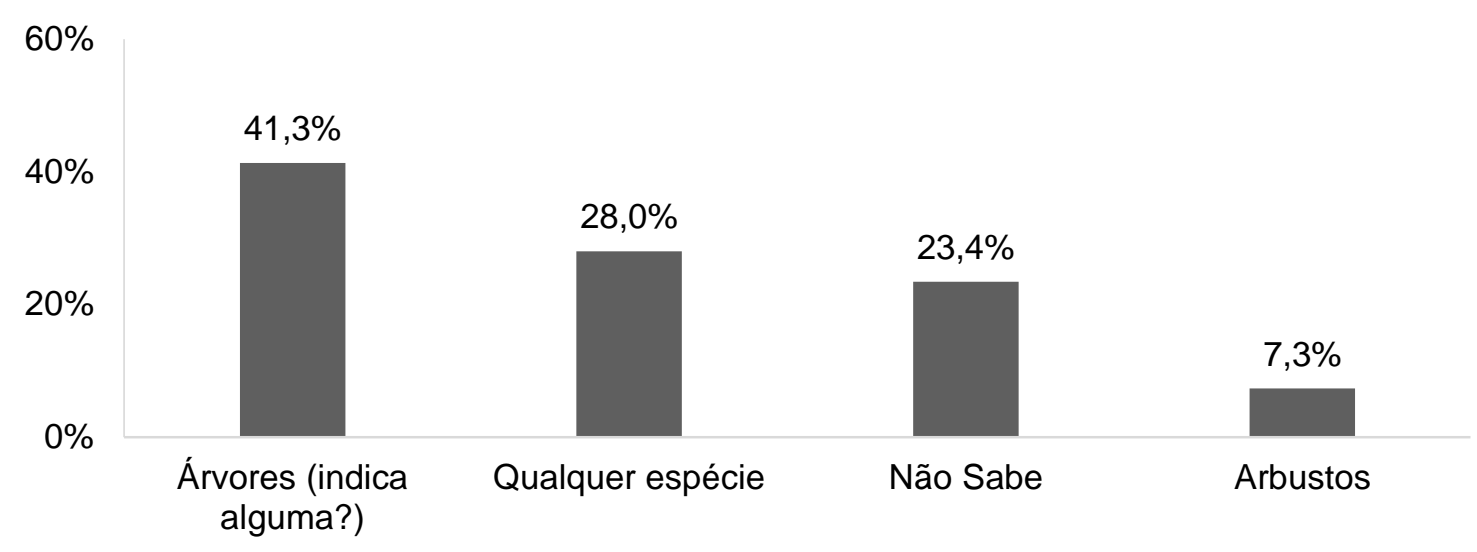

Figura 8. Principais componentes arbóreos citados pelos moradores de lara Ceará para compor a arborização da localidade

Figure 8. Main tree components cited by residents of lara (CE) to compose afforestation of the locality

Foi possível constatar que uma parte dos entrevistados apresentou dificuldade ou mostraram expressões que evidenciaram não saber definir os termos "arbusto" e "árvore", sendo necessário em alguns casos que os pesquisadores diferenciassem esses termos.

Pesquisas com esse escopo são necessárias e podem ajudar na difusão de ideias relacionadas as questões ambientais, e o papel das florestas urbanas na cidade. De modo geral, as pessoas que participaram da pesquisa que eram leigas em alguns termos como "arborização urbana" e a própria diferença entre o que é um "arbusto" e uma "árvore" jamais serão as mesmas pois um elo entre essas pessoas e esses termos foi criado.

Dessa forma, esses dados reforçam a ideia de que o saber não pode ficar concentrado apenas na comunidade científica, sendo necessário que ações como essa sejam incentivadas e 
propagadas para otimização de cidadãos mais conscientes do meio o qual estão inseridos e do valor do seu patrimônio público, que são as "florestas urbanas".

Os resultados evidenciaram que $47 \%$ dos entrevistados preferem Azadirachta indica A. Juss (nim) para compor a arborização do Distrito de lara, 15\% preferem Prosopis juliflora (Sw.) DC (algaroba), 6\% citaram Terminallia Catappa L, (castanhola), 3\% Handroanthus impetignosus (Mart. Ex DC) Mattos (ipê), 3\% Licania rígida (Benth.) Sothers \& Prance (oticica), 3\% Tabebuia aurea (Silva Manso) Benth. \& Hook.f. ex S.Moore (craibeira) 2\%, Bauhinia forficata Link 2\% (pata de vaca) e Ficus benjamina L, (fícus) $2 \%$ e 19\% expressaram o desejo por frutíferas e outros (Tabela 2).

Tabela 2. Principais espécies citadas pelos moradores de lara, Ceará para compor a arborização urbana da localidade

Table 2. Major species cited by lara's (CE) residents to compose the urban afforestation of the locality

\begin{tabular}{lcc}
\hline Espécies & Frequência Absoluta & Frequência Relativa (\%) \\
\hline Azadirachta indica (Nim) & 29 & $46,8 \%$ \\
Prosopis juliflora (Algaroba) & 9 & $14,5 \%$ \\
Terminallia Catappa (Castanhola) & 4 & $6,5 \%$ \\
Handroanthus impetignosus (Ipê) & 1 & $3,2 \%$ \\
Licania rigida (Oiticica) & 1 & $3,2 \%$ \\
Tabebuia aurea (Craibeira) & 2 & $3,2 \%$ \\
Bauhinia forficata (Pata de Vaca) & 2 & $1,6 \%$ \\
Ficus benjamina (Fícus) & 2 & $1,6 \%$ \\
Frutíferas/Outras & 12 & $19,4 \%$ \\
\hline
\end{tabular}

A cultura da ( $A$. indica), foi introduzida no Brasil entre os anos de 1986 e 1989 pela Fundação Instituto Agronômico do Paraná (IAPAR), por produzir lenha de boa qualidade, folhas com alto potencial para produtos inseticidas, fungicidas e defensivos agrícolas, e de fácil crescimento, diante do potencial da espécie, na década de 90 a cultura ganhou lugar no país e passou a ser propagada sem muito embasamento técnico em vários estados e regiões do Brasil desde o clima tropical semiárido até chuvoso (NEVES; CARPANEZZI, 2009), esse mesmo padrão de implementação se repete para a espécie ( $P$. juliflora), segunda espécie mais citada como preferência dos participantes dessa pesquisa.

Esse padrão de implantação de algumas espécies que segue "um modismo de uma determinada época", a exemplo da disseminação da ( $A$. indica) acaba contribuindo para que um elevado número de árvores de uma única espécie seja implementada em uma área ou em centros urbanos, muitas vezes espécie exóticas que por apresentarem crescimento rápido acaba ganhando mais espaço nas preferencias de muitas pessoas como constatado nessa pesquisa.

Tal fato poderia ser minimizado, se os estados fixassem ou promovessem a criação de manuais com listas de espécies invasora, exóticas e indicação de espécies nativas a serem 
implantadas de acordo com cada região e também a promoção e divulgação desses manuais para que a população tenha acesso a essas informações. De acordo com Biondi (2015), se faz necessário práticas educativas tanto para a produção de mudas em viveiros e/ou hortos florestais para que priorizem a produção de espécies nativas. Tais ações são fundamentais para a promoção da educação ambiental mesmo que de forma indireta como também como também se constitui fator essencial para a disseminação de espécies nativas.

Os resultados encontrados aqui são diferentes dos de Melo e Piacentini (2011), em uma pesquisa sobre a diversidade da arborização urbana no município de Colorado (RS), esses pesquisadores puderam constatar que $84 \%$ dos entrevistados optaram pelo plantio de espécies nativas para compor a arborização de Colorado (RS) evidenciando assim o grau de sensibilização e conscientização dos moradores de Colorado (RS) em relação a importância das espécies nativas na arborização urbana.

Grande parte dos entrevistados indicou $A$. indica como opção para compor a arborização da localidade desse estudo e acrescentaram que plantariam essa espécie porque cresce rápido. Por outro lado, os entrevistados que citaram $H$. impetignosus, L. rígida e $T$. aurea, enfatizaram que não plantariam A.indica e nem $F$. benjamina pelos problemas enfrentados com essas espécies. Quando questionadas o porquê os entrevistados acrescentam que "já ouviram falar que a A.indica causa a destruição das abelhas" e/ou que o $F$. benjamina já invadiram a tubulação de suas casas e/ou de pessoas próximas".

As pessoas que citaram as espécies oiticica L. rígida com $3 \%$ e craibeira $T$. aurea com $3 \%$, acrescentaram que eram espécies que antes existiam na localidade que hoje não existe mais e foram capazes de assimilar memorias de tempos passados a esse grupo de plantas. Os resultados indicam que uma parcela mínima dos entrevistados optou por espécies nativas, e demostraram o grau de sensibilização desse pequeno grupo de pessoas quanto a importância de um local arborizado com espécies nativas. Esses resultados reforçam a importância da arborização urbana não só sobre a ótica dos benefícios ambientais como melhoria do microclima, redução da poluição atmosférica entre outros, mas também enaltece a importância da arborização sobre os benefícios psicossociais gerados por uma arborização bem planejada.

\section{CONCLUSÕES}

A análise da percepção ambiental dos moradores do Distrito de lara-CE mostrou que apenas $37,3 \%$ dos entrevistados conheciam o significado do termo "arborização urbana", e $62,7 \%$ revelaram que desconheciam totalmente o termo.

Os moradores do Distrito de lara-CE compreendem os benefícios da arborização urbana e indicaram como principal vantagem o fornecimento de sombra, beleza estética e redução da 
temperatura e como principal desvantagem a redução da iluminação no local, sujeiras de ruas e calçadas e problemas com rede elétrica ou telefônica. Boa parte dos entrevistados denotou a prefeitura como principal responsável pela arborização da localidade, no entanto, um percentual expressivo dos entrevistados não se excluiu das responsabilidades que os mesmos possuem como cidadãos.

\section{REFERÊNCIAS}

ALMEIDA, D. N.; RONDON NETO, R. M. Análise da arborização urbana de duas cidades da região norte do Estado de Mato Grosso. Revista Árvore, Viçosa, v. 34, n. 5, p. 899-906, 2010.

ARAÚJO, J. L. O.; ARAÚJO, A. C.; ARAÚJO, A. C. Percepção ambiental dos residentes do bairro Presidente Médici em Campina Grande, PB, no tocante à arborização local. Revista da Sociedade Brasileira de Arborização Urbana, Curitiba, v.5, n.2, p.1-14, 2010.

BIONDI, D. Fragmentos Florestais e Áreas Protegidas Urbanas. In: BIONDI, D.(Org) Floresta Urbana. Curitiba: Editora UFPR, 2015. p 29-48.

BOBROWSKI, R.; BIONDI, D. Percepção e preferência popular por atributos estéticos e ecológicos na composição da arborização de ruas. Floresta, Curitiba, PR, v. 46, n. 1, p. 123133, 2016.

BRASIL. Lei no 10.257, de 10 de julho de 2001. Regulamenta os arts. 182 e 183 da Constituição Federal, estabelece diretrizes gerais da política urbana e dá outras providências. Disponíveis em: http://www.planalto.gov.br/ccivil_03/leis/leis_20 01//10257.htm>. Acesso em: 25 de fev. 2019.

COMPANHIA ENERGÉTICA DE MINAS GERAIS (CEMIG). Manual de arborização. Belo Horizonte MG: Cemig/Fundação Biodiversitas, 2011. 111p.

FARIA, D. C.; DUARTE, J. M.; PINTO, D. M.; ALMEIDA, F. S. Arborização urbana no município de Três Rios-RJ espécies utilizadas e a percepção de seus benefícios pela população. Revista da Sociedade Brasileira de Arborização Urbana, Curitiba, v.8, n.2, p58-67, 2013.

GROSS; A.; DORS, P.; CAMPOS; K. A., SILVA, A. C.; HIGUCHI, P. Percepção dos moradores e avaliação da arborização em bairros periféricos na cidade de Lages, SC. Revista da Sociedade Brasileira de Arborização Urbana, Curitiba, v.7, n.2, p.24-36, 2012.

HERMANN, B. M.; HADDAD, E. A. Mercado imobiliário e amenidades urbanas: a view through the window. Estudos Econômicos, São Paulo, v. 35, n. 2, p. 237-269, 2005.

HO, T. L.; KOVALSYKI, B.; ZAMPRONI, K.; BIONDI, D. Percepção dos moradores sobre a arborização de ruas da região central de Mandirituba/PR. Revista da Sociedade Brasileira de Arborização Urbana, Piracicaba, v. 10, n. 3, p. 14-23, 2015.

INSTITUTO BRASILEIRO DE GEOGRAFIA E ESTATÍSTICA (IBGE). Censo Demográfico 2010. Disponível em: <http://www.cidades.ibge.gov.br> Acesso em: 20 fev. 2019

LOURENÇO, J. S. G. Percepção da população sobre a arborização da cidade de São João DelRei, Minas Gerais. Revista da Sociedade Brasileira de Arborização Urbana Piracicaba, v. 12, n. 2, p. 62-72, 2017. 
MELO, E. F. R. Q.; PIACENTINI, C. A. M. Diversidade da arborização urbana no município de Colorado (RS). Ambiência, Guarapuava, v. 7, n. 2, p. 339-352, 2011.

NEVES, E.J.M.; CARPANEZZI, A.A., Prospecção do cultivo do nim (Azadirachta indica) no Brasil. Colombo: EMBRAPA Florestas, 2009.

NOVAIS, D. B.; SOUTO, P. C.; BARROSO. R. F.; CAMAÑO. J. D. Z.; FERREIRA. V. S. G. Arborização na cidade de Santa Helena na Paraíba: A percepção dos seus munícipes. Revista da Sociedade Brasileira de Arborização Urbana, Curitiba, v. 12, n. 1, p. 31-45, 2017.

PIZZIOLO, B. V.; TOSTES, R.; SILVA, K.; ARRUDA, V. M. Arborização urbana: Percepção ambiental dos moradores dos bairros Bom Pastor e Centro da cidade de Ubá/MG. Revista Eletrônica em Gestão, Educação e Tecnologia Ambiental, Santa Maria, v. 18, n. 3, p.11621169, 2014.

RIBEIRO, V. A. Percepção Ambiental de Gestores Sobre as Áreas Verdes em Instituição de Ensino Superior. Revista de Gestão Ambiental e Sustentabilidade, São Paulo, v. 7, n. 2, p. 340-358, 2018.

RIBEIRO, F. A. B. S. Arborização urbana em Uberlândia: percepção da população. Revista da Católica, Uberlândia, v. 1, n. 1, p. 224-237, 2009.

RODRIGUES, T. D.; MALAFAIA, G.; QUEIROZ, S. É. E.; RODRIGUES, A. S. L. Percepção sobre arborização urbana de moradores em três áreas de Pires do Rio - Goiás. Revista de estudos ambientais, Blumenau, v.12, n. 2, p. 47-61, 2010.

ROPPA, C., FALKENBERG, J. R., STANGERLIN, D. M., BRUN, F. G. K., BRUN, E. J.; LONGHI, S. J. Diagnóstico da percepção dos moradores sobre a arborização urbana na vila estação colônia - bairro Camobi, Santa Maria - RS. Revista da Sociedade Brasileira de Arborização Urbana, Curitiba, v. 2, n. 2, p. 11-30, 2007.

SANTOS, M. O., MAIA, L. P. S. S., OliVEIRA, E. D., SILVA NETO, J. C. A., CELLA, W. Percepção ambiental sobre a arborização urbana no bairro santa Tereza, Tefé, Amazonas, Brasil. O Espaço Geográfico em Análise, Curitiba, v.44, p. 231 - 241, 2018.

SILVA, T. V.; BERNARDES, A. M. A.; MOURA, T. M.; Percepção dos moradores sobre a arborização urbana do município de Iporá-GO. In: V Congresso Estadual de Iniciação Científica e Tecnológica do IF Goiano, 2016, Iporá. Anais... Iporá: 2016. p. 1-2.

SOUZA, M. A. S.; SOUTO, P. C.; FERNANDES, S. P. S.; NEVES, A. A.; LIMA, F.; SOUTO, J. S. Percepção da população relacionada à arborização urbana de praças no centro da cidade de Patos-PB. Agropecuária científica no semiárido, Patos, v. 12, n. 4, p. 368-375, 2017.

TRIOLA, M. F. Introdução à Estatística. 7. ed. Rio de Janeiro: LTC, 1999

ZEM, L. M.; BIONDI, D. Análise da percepção da população em relação ao vandalismo na arborização viária de Curitiba - PR. Revista da Sociedade Brasileira de Arborização Urbana, Piracicaba, v.9, n.3, p 86-107, 2014. 